\title{
Textiles printing using microencapsulated pigments in biodegradable
} thickeners

\author{
Meram S. Abdelrahman ${ }^{1}$, Sahar H. Nassar ${ }^{1 *}$, Hamada Mashaly ${ }^{1}$, Safia Mahmoud ${ }^{1}$, Dalia \\ Maamoun ${ }^{2}$ \\ ${ }^{1}$ Dyeing, Printing and Auxiliaries Department, Textile Research Division, National Research \\ Centre, Cairo 12622, Egypt \\ ${ }^{2}$ Faculty of Applied Arts, Helwan University, Cairo, Egypt \\ ${ }^{*}$ Corresponding author: sh.wahab@nrc.sci.eg
}

\begin{abstract}
Micro-encapsulated pigments were formulated into biodegradable printing pastes and their properties were analyzed. The pigment was used as the core material and polylactic-based biodegradable thickener was used as the wall-former. Cotton/polyester blend fabric was printed with micro-encapsulated pigment using screenprinting technique without dispersing agents, penetrating agents, leveling agents or other auxiliaries. Microencapsulated pigment has been characterized in terms of average particle size and size distribution, morphological structure and elemental composition using scanning electron microscopy (SEM) and energy dispersive X-ray analysis (EDX). The variations in viscosity and paste stability were observed upon storing over 7 days at ambient temperature. The micro-encapsulation process afforded better colorfastness properties against light, washing, rubbing, and perspiration.
\end{abstract}

Keywords: Microcapsules, Thickener, Polylactic, Biodegradable, Printing

\section{Introduction}

Pigments are a significant set of colorants that have been widely used in the coloration technology processes such as inks, paints and textile printing pastes. Such variety of applications for pigments results from their excellent properties such as photosensitivity, color strength, brilliance and transparency. However, the poor dispersion capability, poor colorfastness, and low weather durability are major problems for organic pigments in various applications. Organic pigments possess very poor solubility in aqueous environment. Therefore, they are generally employed in a dispersion form in presence of dispersing agent. However, traditional pigment dispersion generally has large particles, broad particle size distribution and low stability because particles aggregate easily, and consequently limiting their application in textile printing [1-6].

Micro-encapsulation is an extensively used technique wherein an active interior substance is microencapsulated in an exterior substance, usually polymer, with low permeability. The inner substance in the microcapsule is usually known as a core, while the outer substance is called a shell [7-11]. Microencapsulation technology has been applied in several fields such as pharmaceutical industry, fertilizers, cosmetics, and dyeing of textile fabrics. Many studies have been performed on the preparation, stabilization, and characterization of aqueous well-dispersed nano/micro-scale materials. Encapsulation is a promising method to enhance materials processing, environmental protection such as UV and $\mathrm{pH}$, and prevent agglomeration. Microcapsules introduce the advantages that they are adjustable; the active core materials can be liberated at a controlled rate a transporter shell. Micro-encapsulated colorants have been paid attention in a variety of textiles applications. Pigments are ideal for micro-encapsulation [12-18].

The current study has employed micro-encapsulation of pigment that has led to a new environmentally safe technique for textile printing in the absence of auxiliaries using disperse dyes microencapsulated with polyurea. In this study, scanning electron microscopy (SEM) and energy dispersive X-ray analysis (EDX) were used to gain information about the quality of the micro-encapsulated pigments, as well as their printing performance on polyester/cotton blend fabric.

\section{Experimental details}

\subsection{Materials and substrates}

Scoured polyester/cotton textile blend fabrics were supplied from Misr El-Mahallah for Spinning and Weaving Company, Mahalla El-Kobra, Egypt. The fabrics were further treated with a solution containing $2 \mathrm{~g} / \mathrm{L}$ nonionic detergent (Hostapal $\AA^{\circ} \mathrm{CV}$-Clariant), at $60^{\circ} \mathrm{C}$ for 30 minutes, then the fabrics were thoroughly rinsed with tap water and air-dried at room temperature.

Printofix Binder MTB was kindly supplied by Clariant. Pigment fast Yellow 2GB was kindly supplied by EIMahalla El-Kobra Company, El-Mahalla, Egypt. 


\subsection{Preparation of pigment printing paste}

The printing paste of pigment was prepared according to the following recipe:

\section{Pigment}

Pigment

Thickener

Binder

Diamonum phosphate

Water

$$
\begin{aligned}
& 40 \\
& Y \\
& 40 \\
& 10 \\
& X
\end{aligned}
$$

1000

\subsection{Analysis and measurements}

\section{Synthesis of triglyceride polylactic acid (TGPLA) polymer}

Triglyceride polylactic acid polymers with various molar ratios of glycerol and lactic acid were synthesized via one-step polycondensation procedure as shown in Scheme 1. The typical synthesis is proceeded as follows (for ratio: $50 \% \mathrm{LA}$ to $50 \% \mathrm{GL}$ ): A mixture of lactic acid $(18 \mathrm{~g}, 20 \mathrm{mmol})$ and glycerol $(17.2 \mathrm{~g}, 20 \mathrm{mmol}$ ) was stirred in a $500 \mathrm{~mL}$ conical flask, while raising the temperature to $90^{\circ} \mathrm{C}$. 2-3 drops of concentrated sulfuric acid were added. The reaction was then heated at $100^{\circ} \mathrm{C}$ for additional 20-30 minutes. After cooling, concentrated solution of sodium hydroxide was gradually added to neutralize the reaction mixture. The mixture was then subjected to water evaporation using rotary evaporator to obtain the pure solid content. The polymer composite can also be separated by addition of ethanol to afford a wet gel that can be filtered, dried and milled.

\section{Synthesis of Carboxy Lactic Methacrylate (CLMA) polymer}

$P$ (LA-MAA) polymers of various monomers molar ratios were synthesized from MAA and various molar ratios of LA by a two-step one-pot polymerization procedure shown in Scheme 1. The typical synthesis were proceeded as follows (for the ratio: $50 \%$ LA to 50\% MAA): A mixture of lactic acid $(18 \mathrm{~g}, 20 \mathrm{mmol}$ ) and methacrylic acid $(17.2 \mathrm{~g}, 20 \mathrm{mmol})$ was stirred in a $500 \mathrm{~mL}$ conical flask, while raising the temperature to $90^{\circ} \mathrm{C}$. 2-3 drops of concentrated sulfuric acid were added and the temperature was then raised to $105^{\circ} \mathrm{C}$. The mixture was stirred for 20-30 minutes followed by addition of $\mathrm{N}, \mathrm{N}$-methylene diacrylamide crosslinker $(2 \mathrm{~g})$. After the crosslinker is completely soluble, potassium persulfate $(270 \mathrm{mg}, 1 \mathrm{mmol})$ was added. The reaction was then heated at $105^{\circ} \mathrm{C}$ for additional $10-15$ minutes. Hydroquinone $(110 \mathrm{mg}, 1 \mathrm{mmol})$ was then added to the reaction mixture. After cooling, concentrated solution of sodium hydroxide was gradually added to neutralize the reaction mixture. The mixture was then subjected to water evaporation under vacuum using rotary evaporator to obtain the pure solid content. The polymer composite can also be separated by addition of ethanol followed by filtration of the produced solid [19].

\section{Preparation of microcapsules}

An encapsulator BUCHI B-390 (Inotech, Switzerland) equipped with a $500 \mu \mathrm{m} / 750 \mu \mathrm{m}$ concentric nozzle, a $50 \mathrm{ml}$ syringe and an air pressure solution delivery system was used to prepare microcapsules of thickener with a pigment core. Water solution of CLMA and TGPLA was used as the shell forming phase. Systems saturated with solid $6 \mathrm{M} \mathrm{CaCl} 2$ solution were used as the shell/core forming phase. Microcapsules were produced at a shell flow rate of $44.6 \mathrm{mg} / \mathrm{s}$ and core flow rates of $7.3 \mathrm{mg} / \mathrm{s} \mathrm{or} 40.1 \mathrm{mg} / \mathrm{s}$. The amplitude of the membrane was constant throughout all experiments and its frequency was set to $3000 \mathrm{~Hz}$. Microcapsules were then filtered using cotton fabric.

\section{Morphology and elemental compositions of metal oxides on fabrics surfaces}

Field emission scanning electron microscope (FE-SEM) on a Quanta FEG 250 (Czech Republic), was used to investigate the morphology, cooped with Energy Dispersive Spectroscopy analysis (TEAM -EDX Model). The EDX measurements were reported at $20 \mathrm{kV}$ accelerating voltage and $21 \mathrm{~mm}$ working distance. 


\section{Color strength}

The colorimetric analysis of the dyed samples was performed using a Hunter Lab ultra Scan® PRO spectrophotometer. The corresponding colour strength value $(K / S)$ was assessed by applying the Kubelka Munk equation as follows.

$$
K / S=\frac{(1-R)^{2}}{2 R}
$$

Where, $\mathrm{R}$ is the decimal fraction of the reflection of the dyed fabric, $\mathrm{K}$ is the absorption coefficient, and $\mathrm{S}$ is the scattering coefficient.

\section{Colorfastness properties}

The printed samples were subjected to rubbing, washing, perspiration and light according to standard ISO methods, ISO 105-X12 (1987), ISO 105-CO4 (1989), ISO105-EO4 (1989), ISO 105-BO2 (1988) respectively.

\section{Results and Discussion}

It is clear from the data that the higher K/S value was achieved upon using encapsulated pigment. It is obviously seen also that even at lower pigment concentration at $0.5 \%$ wof, the $\mathrm{K} / \mathrm{S}$ was increased from 6.26 to 14.38 , i.e. by almost $26.04 \%$. The printing paste samples prepared via encapsulated thickener/pigment system and printed was found to acquire the highest K/S was chosen and subjected to overall color fastness measurements. The printed untreated cotton/polyester blend fabric was also measured under the same conditions for the sake of comparison. Tables 1 and 2 represent the data of overall colour fastness properties, i.e. for washing, rubbing (wet and dry), and perspiration (acidic and alkaline). on: (a) the nature of dye used, (b) the kind of fabric, (c) the nature of the nano-particles used in pretreatment and its concentration. However, it is also clear from Tables 1 and 2 that in all cases the values of the overall colour fastness for the pretreated fabrics is nearly equal or slightly better than that of the untreated fabric.

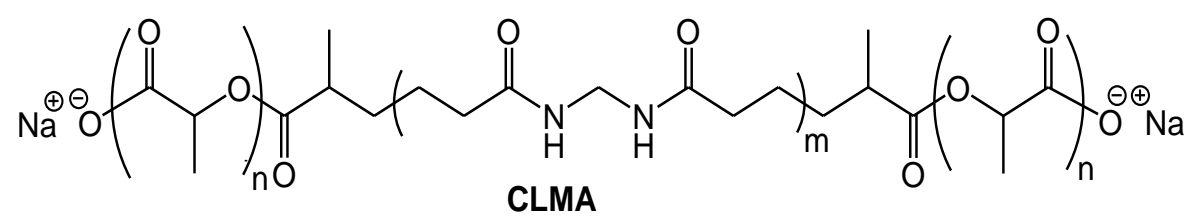<smiles>CC(OCC(OC(C)C(=O)O[Na])C(C)(C)OC(C)C(=O)O[Na])C(=O)O[Na]</smiles>

Figure 1. Chemical structures of CLMA and TGPLA polymers. 

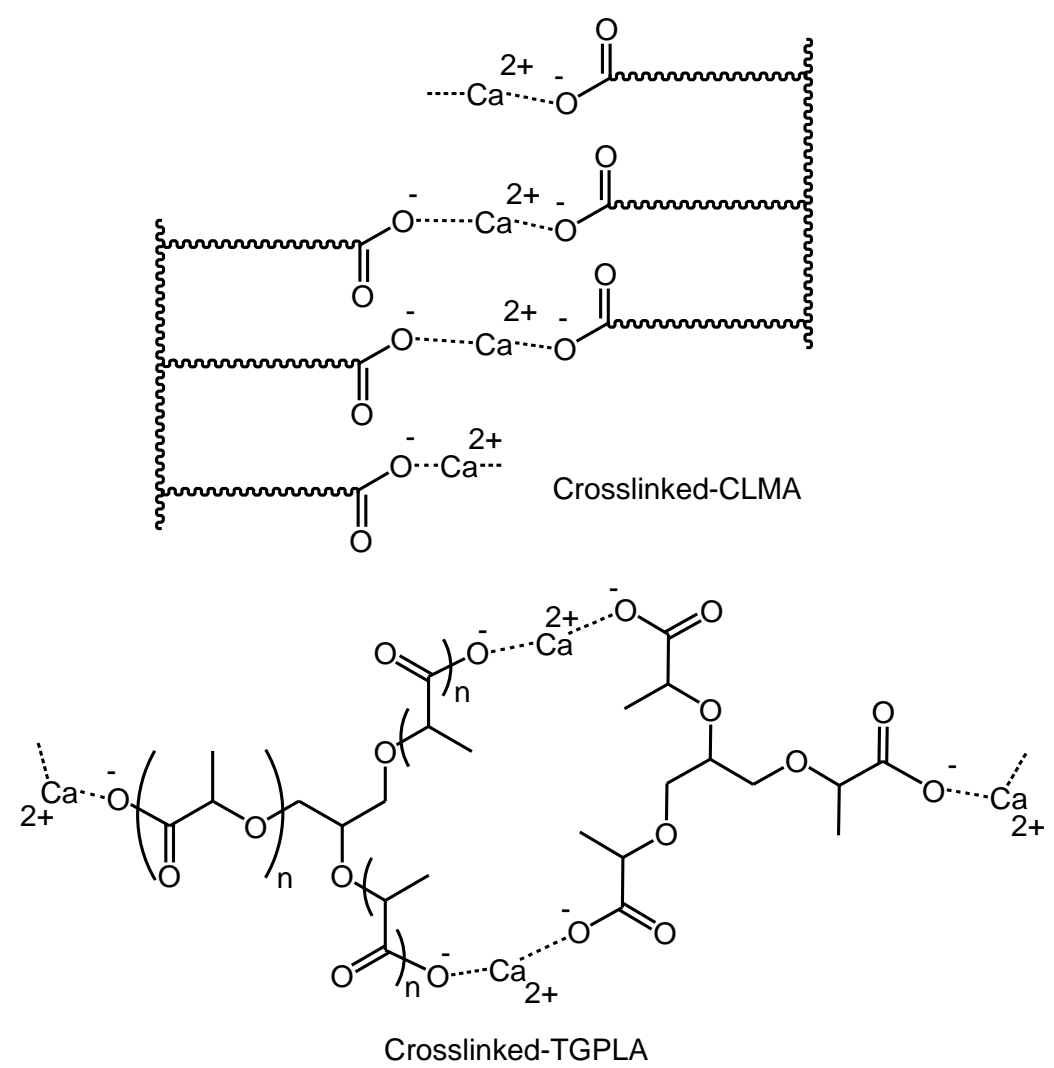

Figure 2. Synthetic CLMA and TGPLA polymers crosslinked by calcium ions.

Both CLMA and TGPLA polymers (Figure 1) were prepared and characterized in Chapters 2 and 3 . Because of the availability of the free carboxylic sodium salt, when CLMA and TGPLA are added into a solution of calcium ions $\left(\mathrm{CaCl}_{2}\right)$, the divalent calcium ions replace the monovalent sodium ions in the polymer. Each calcium ion can connect to two of the polymer strands. This is called cross-linking as shown in Figure 2. 
Table 1. Comparison between $\mathbf{k} / \mathbf{s}$ and fastness properties of Cotton/Polyester fabric sample printed with prepared CLMA composite thickener along with those printed using different CLMA composite technical encapsulated techniques when pigment used.

\begin{tabular}{|c|c|c|c|c|c|c|c|c|c|}
\hline \multirow{4}{*}{$\begin{array}{l}\text { Thickening } \\
\text { agent used }\end{array}$} & \multirow{4}{*}{$\begin{array}{l}\text { Storing } \\
\text { Time }\end{array}$} & \multirow{4}{*}{$\mathrm{K} / \mathrm{S}$} & \multicolumn{7}{|c|}{ Fastness properties } \\
\hline & & & \multicolumn{2}{|c|}{ Rubbing } & \multicolumn{2}{|c|}{ Washing } & \multicolumn{2}{|c|}{ Perspiration } & \multirow{3}{*}{$\begin{array}{l}\text { Light } \\
\text { fastness }\end{array}$} \\
\hline & & & & & & & Acidic & Alkaline & \\
\hline & & & Dry & Wet & St. & Alt & St. & Alt. & \\
\hline $\begin{array}{c}\text { Blank (CLMA) } \\
\text { composite }\end{array}$ & $\mathrm{F}$ & 7.77 & $4-5$ & $4-5$ & $4-5$ & $4-5$ & $4-5$ & $4-5$ & 7 \\
\hline $\begin{array}{c}\text { Blank (CLMA) } \\
\text { composite }\end{array}$ & S1 & 10.43 & $4-5$ & $4-5$ & $4-5$ & $4-5$ & $4-5$ & $4-5$ & 7 \\
\hline $\begin{array}{c}\text { Blank (CLMA) } \\
\text { composite }\end{array}$ & S2 & 8.85 & $4-5$ & $4-5$ & $4-5$ & $4-5$ & $4-5$ & $4-5$ & 7 \\
\hline $\begin{array}{c}\text { Encapsulated } \\
\text { (CLMA) } \\
\text { composite }\end{array}$ & $\mathrm{F}$ & 6.18 & $4-5$ & $4-5$ & $4-5$ & $4-5$ & $4-5$ & $4-5$ & 7 \\
\hline $\begin{array}{c}\text { Encapsulated } \\
\text { (CLMA) } \\
\text { composite }\end{array}$ & S1 & 8.21 & $4-5$ & $4-5$ & $4-5$ & $4-5$ & $4-5$ & $\overline{4-5}$ & 7 \\
\hline $\begin{array}{c}\text { Encapsulated } \\
\text { (CLMA) } \\
\text { composite }\end{array}$ & S2 & 7.93 & $4-5$ & $4-5$ & $4-5$ & $4-5$ & $4-5$ & $4-5$ & 7 \\
\hline $\begin{array}{l}\text { Encapsulated } \\
\text { pigmented } \\
\text { (CLMA) } \\
\text { composite }\end{array}$ & $\mathrm{F}$ & 10.53 & $3-4$ & $4-5$ & $4-5$ & $4-5$ & $4-5$ & $4-5$ & 7 \\
\hline $\begin{array}{l}\text { Encapsulated } \\
\text { pigmented } \\
\text { (CLMA) } \\
\text { composite }\end{array}$ & S1 & 5.28 & $3-4$ & 4 & $4-5$ & $4-5$ & $4-5$ & $4-5$ & 7 \\
\hline $\begin{array}{l}\text { Encapsulated } \\
\text { pigmented } \\
\text { (CLMA) } \\
\text { composite }\end{array}$ & S2 & 10.33 & $3-4$ & 4 & $4-5$ & $4-5$ & $4-5$ & $4-5$ & 7 \\
\hline
\end{tabular}

CLMA, Encapsulated (CLMA) and Encapsulated pigmented (CLMA) composite synthetic thickeners are prepared using $98 \%$ lactic acid respectively; F: Freshly prepared ; S1: Stored for 3 dyes; S2: Stored for 7 dyes; St: Staining 
Table 2. Comparison between $\mathbf{k} / \mathbf{s}$ and fastness properties of Cotton/Polyester fabric sample printed with prepared TGPLA composite thickener along with those printed using different TGPLA composite technical encapsulated techniques when pigment used.

\begin{tabular}{|c|c|c|c|c|c|c|c|c|c|}
\hline \multirow{4}{*}{$\begin{array}{c}\text { Thickening agent } \\
\text { used }\end{array}$} & \multirow{4}{*}{$\begin{array}{l}\text { Storing } \\
\text { Time }\end{array}$} & \multirow{4}{*}{$\mathrm{K} / \mathrm{S}$} & \multicolumn{7}{|c|}{ Fastness properties } \\
\hline & & & \multicolumn{2}{|c|}{ Rubbing } & \multicolumn{2}{|c|}{ Washing } & \multicolumn{2}{|c|}{ Perspiration } & \multirow{3}{*}{$\begin{array}{l}\text { Light } \\
\text { fastness }\end{array}$} \\
\hline & & & & & & & Acidic & Alkaline & \\
\hline & & & Dry & Wet & St. & Alt & St. & Alt. & \\
\hline $\begin{array}{l}\text { Blank (TGPLA) } \\
\text { composite }\end{array}$ & $F$ & 7.40 & $4-5$ & $4-5$ & $4-5$ & $4-5$ & $4-5$ & $4-5$ & 7 \\
\hline $\begin{array}{l}\text { Blank (TGPLA) } \\
\text { composite }\end{array}$ & S1 & 3.90 & $4-5$ & $4-5$ & $4-5$ & $4-5$ & $4-5$ & $4-5$ & 7 \\
\hline $\begin{array}{l}\text { Blank (TGPLA) } \\
\text { composite }\end{array}$ & S2 & 3.73 & $4-5$ & $4-5$ & $4-5$ & $4-5$ & $4-5$ & $4-5$ & 7 \\
\hline $\begin{array}{c}\text { Encapsulated } \\
\text { (TGPLA) composite }\end{array}$ & $F$ & 6.36 & $4-5$ & $4-5$ & $4-5$ & $4-5$ & $4-5$ & $4-5$ & 7 \\
\hline $\begin{array}{c}\text { Encapsulated } \\
\text { (TGPLA) composite }\end{array}$ & S1 & 7.34 & $4-5$ & $4-5$ & $4-5$ & $4-5$ & $4-5$ & $4-5$ & 7 \\
\hline $\begin{array}{c}\text { Encapsulated } \\
\text { (TGPLA) composite }\end{array}$ & S2 & 7.10 & $4-5$ & $4-5$ & $4-5$ & $4-5$ & $4-5$ & $4-5$ & 7 \\
\hline $\begin{array}{c}\text { Encapsulated } \\
\text { pigmented (TGPLA) } \\
\text { composite }\end{array}$ & $\mathrm{F}$ & 12.57 & 3-4 & 4 & $4-5$ & $4-5$ & $4-5$ & $4-5$ & 7 \\
\hline $\begin{array}{c}\text { Encapsulated } \\
\text { pigmented (TGPLA) } \\
\text { composite }\end{array}$ & S1 & 7.06 & $3-4$ & $4-5$ & $4-5$ & $4-5$ & $4-5$ & $4-5$ & 7 \\
\hline $\begin{array}{c}\text { Encapsulated } \\
\text { pigmented (TGPLA) } \\
\text { composite }\end{array}$ & S2 & 12.12 & 3-4 & 4 & $4-5$ & $4-5$ & $4-5$ & $4-5$ & 7 \\
\hline
\end{tabular}

TGPLA, Encapsulated (TGPLA) and Encapsulated pigmented (TGPLA) composite synthetic thickeners are prepared using 98\% lactic acid respectively; F: Freshly prepared; S1: Stored for 3 dyes; S2: Stored for 7 dyes; St: Staining

In the current work, we study the effects of encapsulation of pigment during printing process of cotton/polyester blend fabric, whereas the pigment is the core and the thickener is the shell. Such encapsulation helps to better disperse the pigment leading to color properties in the pigment properties technology. This study aims to enhance the printing properties of cotton/polyester blend fabric to improve color strecgth and decrease the employed amount of pigment. We utilized triglyceride / polylactic acid (TGPLA) and Carboxy Lactic / Methacrylate (CLMA) in the paste composited thickeners. To achieve this goal, the morphology and size of the prepared thickener/pigment capsules was monitored using scanning electron microscopy (SEM) as shown in Figures 3. The elemental compositions were also investigated by the energy dispersive X-ray spectroscopy (EDX) Figure 3 and Table 3. A close examination of the SEM micrographs signifies an average of $350 \mathrm{~nm}$ of capsules. Samples of cotton/polyester blend fabric was treated with the prepared thickener/pigment formula in both conventional and encapsulation forms. The $\mathrm{K} / \mathrm{S}$ as well as the color fastness properties of the treated and printed samples, in addition to the quantity of used pigment on fabrics was investigated. 

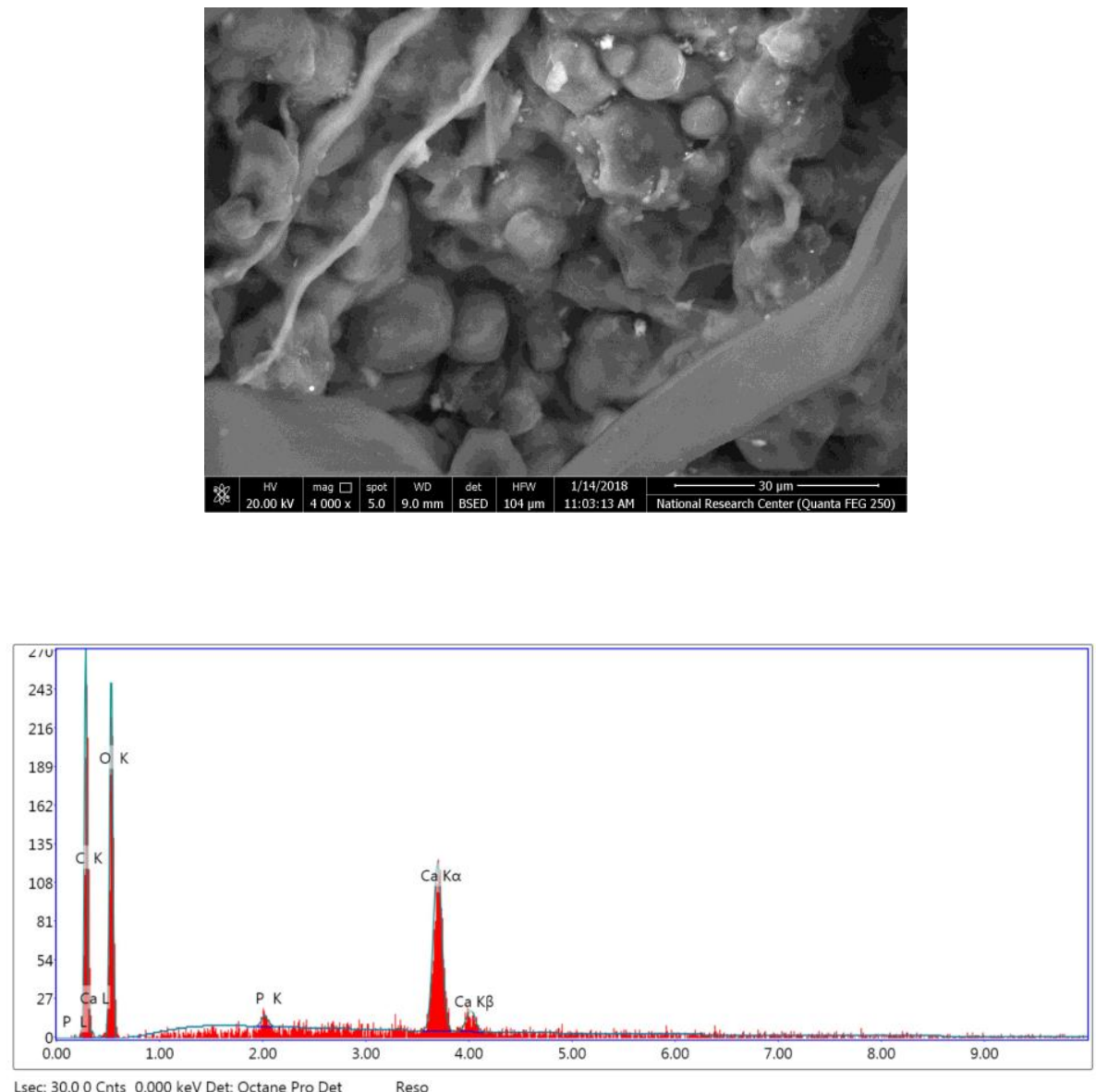

Figure 3. SEM image (top) and EDX diagram (bottom) of CLMA croslinked polymer thickener containing pigment.

Table 3. The composition in weight $\%$ and atomic $\%$ of two different regions for printed cotton fabric

\begin{tabular}{|c|c|c|c|c|c|c|c|c|}
\hline Sample & \multicolumn{2}{|c|}{ C } & \multicolumn{2}{c|}{ O } & \multicolumn{3}{c|}{ P } & \multicolumn{2}{c|}{ Ca } \\
\cline { 2 - 9 } & Wt. \% & At. \% & Wt. \% & At. \% & Wt. \% & At. \% & Wt. \% & At. \% \\
\hline CLMA & 38.83 & 47.4 & 54.85 & 50.26 & 0.31 & 0.15 & 6.01 & 2.2 \\
\hline
\end{tabular}

\section{Conclusions}

$\mathrm{Nano} /$ microscale organic pigments were encapsulated in a synthetic thickener were successfully prepared by using encapsulator. The prepared thickener showed better color stregcth and colorfastness properties. Furthermore, lower amounts of pigments were used. The effective encapsulation was con-firmed by SEM and EDX. Using the encapsulated pigment in a biodegradable synthetic thickener for textile printing is a much simpler, cheaper and environment friendly method. The printed fabrics displayed soft handle and very good colorfastness properties.

\section{Acknowledgements}

We gratefully acknowledge National Research Centre, Cairo, Egypt; for the support of this work.

\section{References}

[1] Heinrich Zollinger, Color chemistry: syntheses, properties, and applications of organic dyes and pigments. John Wiley \& Sons, 2003. 


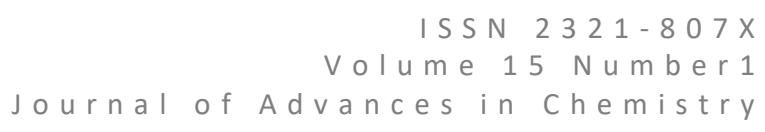

[2] Himadri Panda, A concise guide on textile dyes, pigments and dye intermediates with textile printing technology. Niir Project Consultancy Services, 2013.

[3] Domenick D. Gagliardi, and Robert J. Cicione. "Process for binding pigments to textiles." U.S. Patent 3,661,632, issued May 9, 1972.

[4] R. J. Hannay, "Some Problems in the Application of Pigments for the Coloration of Textiles." Coloration Technology 61, no. 4 (1945): 88-90.

[5] Norman S. Cassel, "Method of coloring textiles with pigments." U.S. Patent 2,342,642, issued February 29, 1944.

[6] Klaus Hunger, ed. Industrial dyes: chemistry, properties, applications. John Wiley \& Sons, 2007.

[160] Antónia Gonçalves, Berta N. Estevinho, and Fernando Rocha. "Microencapsulation of vitamin A: a review." Trends in Food Science \& Technology 51 (2016): 76-87.

[7] R. H. Müller, M. Radtke, and S. A. Wissing. "Nanostructured lipid matrices for improved microencapsulation of drugs." International journal of pharmaceutics 242, no. 1-2 (2002): 121-128.

[8] Eamonn McGee, and Terri L. Lang. "A study of the effects of a micelle encapsulator fire suppression agent on dynamic headspace analysis of fire debris samples." Journal of Forensic Science 47, no. 2 (2002): 267274.

[9] Claude P. Champagne, and Patrick Fustier. "Microencapsulation for the improved delivery of bioactive compounds into foods." Current opinion in biotechnology 18, no. 2 (2007): 184-190.

[10] Simon Benita, ed. Microencapsulation: methods and industrial applications. CRC Press, 2005.

[11] Swapan Kumar Ghosh, ed. Functional coatings: by polymer microencapsulation. John Wiley \& Sons, 2006.

[12] Lauren S. Jackson, and Ken Lee. "Microencapsulation and the food industry." Lebensm. Wiss. Technol 24, no. 4 (1991): 289-297.

[13] Géraldine Hébrard, Valérie Hoffart, Jean-Michel Cardot, Muriel Subirade, and Eric Beyssac. "Development and characterization of coated-microparticles based on whey protein/alginate using the Encapsulator device." Drug development and industrial pharmacy 39, no. 1 (2013): 128-137.

[14] Gm Thilagavathi, and S. Krishna Bala. "Microencapsulation of herbal extracts for microbial resistance in healthcare textiles." (2007).

[15] Gordon Nelson, "Application of microencapsulation in textiles." International journal of pharmaceutics 242, no. 1-2 (2002): 55-62.

[16] Karthik Keyan, T. Ramachandran, O. L. Shamugasundaram, M. Balasubramaniam, and T. Ragavendra. "Microencapsulation of PCMs in textiles: a review." Journal of Textile and Apparel, Technology and Management 7, no. 3 (2012).

[17] Marc Van Parys, "Smart textiles using microencapsulation technology." Functional Coatings (2006).

[18] S. S. Jyothi, A. Seethadevi, K. Suria Prabha, P. Muthuprasanna, and P. Pavitra. "Microencapsulation: a review." Int J Pharm Biol Sci 3 (2012): 509-31.

[19] M. S. Abdelrahman, S. H. Nassar-, H. Mashaly, S. Mahmoud, and D. Maamoun. "Synthesis and Characterization of Biodegradable Synthetic Thickener from Anionic Triglyceride Polylactic Acid."

Applied Ecology and Environmental Sciences 6, no. 2 (2018) 35-47. DOI: 10.12691/aees-6-2-1 